Research Article

\title{
Study on Electric-Magnetic-Acoustic Signal Regularity and Its Correlation during Rock Shear Failure
}

\author{
Huilin Jia $\mathbb{D}^{1,2}$ Yue Niu $\mathbb{D}^{1,3}$ Xiaofei Liu, ${ }^{1,3}$ and Enyuan Wang ${ }^{1,3}$ \\ ${ }^{1}$ State Key Laboratory of Coal Resources and Safe Mining, China University of Mining and Technology, Xuzhou, \\ Jiangsu 221116, China \\ ${ }^{2}$ Department of Vocational and Continuing Education, China University of Mining and Technology, Xuzhou, \\ Jiangsu 221116, China \\ ${ }^{3}$ School of Safety Engineering, China University of Mining and Technology, Xuzhou, Jiangsu 221116, China
}

Correspondence should be addressed to Huilin Jia; hl.j@cumt.edu.cn and Yue Niu; name_niuyue@163.com

Received 8 May 2019; Revised 29 June 2019; Accepted 8 July 2019; Published 18 July 2019

Guest Editor: Grzegorz Lesiuk

Copyright (c) 2019 Huilin Jia et al. This is an open access article distributed under the Creative Commons Attribution License, which permits unrestricted use, distribution, and reproduction in any medium, provided the original work is properly cited.

During mining activities, the deformation and damage of coal rock materials might result in coal rock dynamic disasters, such as rock burst. It leads to serious casualties and property losses. Generally, the occurrence of dynamic failure of coal and rock are caused by shear failure of coal seam. Geophysics signals are generated and related to damage evolution in this loading process. In this paper, sandstone samples were subjected to shear failure laboratory experiments, and the electric-magnetic-acoustic signal regularity was measured and analyzed comparatively. The results indicated magnetic signals were more correlated with stress and acoustic emission (AE) signals, while the amplitude of electric signal fluctuation was larger when main failure occurred. With the increase of sample size and shear strength, the strength of electric-magnetic-acoustic signals increased. The correlation coefficients between the magnetic signal and stress as well as AE energy were superior to those of electric signals. The coupling model between $\mathrm{AE}$ and electric signals was established, which shows good statistical correlation. This study lays the foundations for further interpreting the generation mechanism of the electric signal. It provides a new method to indicate the damage evolution of coal rock materials.

\section{Introduction}

Generally, coal resources play a significant role during the energy consumption, especially for industrial raw materials and electric power production [1-3]. Nevertheless, coal rock dynamic failure and even disasters occur during mining activities, which results in serious casualties and property losses [4-7]. Coal or rock fracture, roof collapse, and fault activation in mines are all accompanied by shear failure, which will further induce mine earthquake, rock burst, coal and gas outburst, and other dynamic disasters $[2,8]$. It is of great significance to determine damage sources and their characteristics for predicting dynamic disasters in coal mines [9-11].

During the damage and failure process of the rock, acoustic emission (AE) signals are generated [12]. Therefore, $\mathrm{AE}$ technology is used to study the expansion and evolution mechanism of cracks $[13,14]$. Khazaei et al. analyzed the variations in $b$ values, energy of acoustic emission for rock specimens during 73 uniaxial compression tests [15]. Liang et al. investigated the mechanical and acoustic emission characteristics of the rock during loading and unloading confining pressures at the postpeak stage [16]. Wang et al. investigated the features of similar material mechanics and concluded that the law of AE behavior and the characteristics of similar material fracture can obtained the regularity of stress and deformation during material loading processes [17]. Kong et al. concentrated on the thermal mechanical properties and $\mathrm{AE}$ characteristics during the deformation and fracture of the rock under the action of continuous heating and after high-temperature treatment [18].

In addition to $\mathrm{AE}$ signals, electromagnetic radiation (EMR) has been recognized and analyzed in rock failure and earthquake precursor observation in early days [19-21]. 
Freund and Sornette revealed the mechanism for the lowfrequency electromagnetic emissions and electric phenomena and conjectured the intermittent and erratic occurrences of EMR signals are a consequence of the progressive and of their release, which provided a conductive pathway [22]. Gade et al. argued that the electromagnetic signals are generated as a result of the collaborative consequence of charge separation, relaxation, and vibration of charged crack surface during the growth of cracks [23]. Interestingly, Carpinteri et al. reported that growth of both microcracks and macrocracks would lead to EMR signals [24]. Wang et al. reported that coal rock materials could produce ultralow frequency (ULF) EMR signals during the damage and failure processes, and the change trend of the signals was well similar to stress and AE signals [25]. To predict the collapses more accurately using EMR, a loaded coal rock EME coupling model based on statistical damage mechanics was established [26]. Kong et al. studied the timevarying characteristics of EMR during three metamorphic grades of the coal-heating process [27].

Owing to the complexity of rock outburst, the precursor signals of AE and EMR might be not very obvious, but with improvements in monitoring methods, the electric signals are beginning to be analyzed gradually [11, 28-30]. Freund has tried to establish the physically coherent model for resistivity changes, ground potentials, and electromagnetic behavior and explained the mechanism of earthquake-related electrical signals and emission [31]. Li et al. studied the surface potential of coal during different fracture modes, including uniaxial compression, tensile fracture, and three-point bending and concluded that surface potential was produced during the fracture of coal and that it had a good correspondence to the load [32]. To explain the mechanism of electric potential (EP), the change law and distribution characteristics of electric potential were tested with the precracked rock samples, and free charges were found to be produced at the tip of the cracks and the newly formed crack surface [33].

Several studies on AE, EMR, and electric signals have been published. However, studies evaluating these signals in shear failure, especially rock shear failure, are scarce. Besides, the correlation characteristics of electric-magneticacoustic signal regularity were not reported. In this paper, under shear failure, the electric-magnetic-acoustic signal regularity of sandstone was studied, and the impact of sample size on experimental results was analyzed. Furthermore, the correlation characteristics among electric signals, EMR, AE, and stress were illustrated. Variation laws of the electric signal were interpreted by establishing an acoustic-electric coupling model. It is promising to further reveal the dynamic disaster process of coal rock materials and perfect the EMR theory as well as the corresponding test equipment.

\section{Materials and Experimental Procedure}

2.1. Material Preparation. The tested rock samples were collected from roof sandstones of Sanhejian Coal Mine in Xuzhou, China. According to the International Society for Rock Mechanics (ISRM) standard, samples were prepared and processed in Strata Control Experimental Center, State Key Laboratory of Coal Resources, and Safety Mining of China University of Mining and Technology. After sample coring, two types of specimen $(50 \mathrm{~mm} \times 50 \mathrm{~mm} \times 100 \mathrm{~mm}$ and $50 \mathrm{~mm} \times 50 \mathrm{~mm} \times 50 \mathrm{~mm}$ ) were prepared. The prepared standard specimen was labeled and kept in a glass container that was sealed up with Vaseline to preserve the original state of the specimen.

2.2. Test System. The experimental system mainly includes hydraulic loading devices, data-acquisition system, various sensors, etc. (Figure 1). Loading system: the control system is an electrohydraulic servo pressure-testing machine (YAW4306), and the maximum pressure is $3000 \mathrm{kN}$. The loading process can fully realize program control and can simultaneously collect parameters such as stress and displacement during the whole loading process at high speed. The LB-IV electric signal data-acquisition system was used to collect the low-frequency electric signal during deformation and failure process of the rock. Data sampling frequency could be set arbitrarily below $1000 \mathrm{~Hz}$. The frequency of sensors used to collect the low-frequency and acoustic and magnetic signals is higher than that of the lowfrequency electric signal, so the CTA-1 acoustic-electric dynamic high-speed data-acquisition system, manufactured by Physical Acoustics (American), was used.

Signal sensors: the copper electrodes (Figure 2(a)) were used to receive low-frequency $(<1 \mathrm{kHz})$ electric signals. $\mathrm{AE}$ sensors (Figure 2(b)) with $42.3 \mathrm{kHz}$ resonant frequency were used to monitor acoustic signals, and the ferrite rod antennas (Figure $2(\mathrm{c})$ ) of low frequency $(1 \mathrm{kHz}$ and $5 \mathrm{kHz})$ and common frequency $(300 \mathrm{kHz})$ were used to collect magnetic signals. In the experiments, the cooper electrodes and the acoustic emission sensors were fixed onto the rock sample surface using adhesive tapes. A Vaseline coupling agent was used at the contact surface to ensure the elastic wave is received by the sensors. The ferrite rod antennas were arranged around the specimen, less than $10 \mathrm{~cm}$ away from the specimen.

2.3. Test Scheme. Shear strength of the rock is the tangential stress on the shear surface when rocks suffer shear failure and is the ultimate strength of the rock at shear failure. The oblique compression molding method is widely used to test the shear strength of the rock, with which the normal stress $(\sigma)$ and shear stress $(\tau)$ on the shear failure surface can be calculated.

The laboratory rock shear experiment and the layout of sensors are shown in Figure 3. Two electrodes were pasted on the specimen surface, about $10 \mathrm{~mm}$ to two sides of the shear surface $A B$, respectively, and the third electrode was pasted on the upper left corner of the rear surface of the specimen, $10 \mathrm{~mm}$ away from the specimen edge. The AE sensor was attached at the bottom left corner of the rear surface of the specimen, $5 \mathrm{~mm}$ away from the specimen edge. The prepared rock specimen was placed in between two angle-variable shear clamps, and shear force was applied onto the specimen by controlling the loading rate. During the loading process, the 


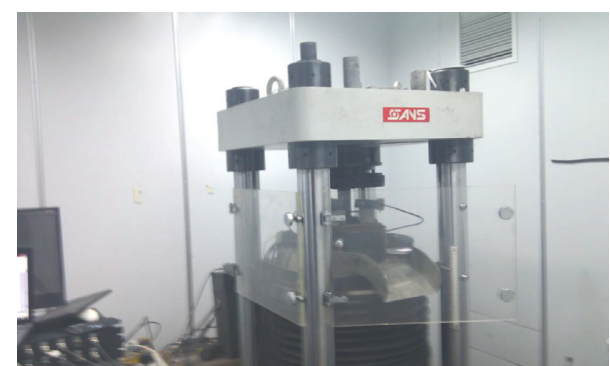

Figure 1: Experimental system.

electric, acoustic, and magnetic signals were monitored simultaneously. Finally, the sample would experience failure along the preset shear surface of $\mathrm{AB}$.

\section{Electric-Acoustic-Magnetic Signals upon Rock Shear Failure}

3.1. Sample 1. The stress law and electric-magneticacoustic signal regularity of sample 1 are presented in Figures $4(\mathrm{a})-4(\mathrm{~h})$. The size of shear failure surface was about $50 \mathrm{~mm} \times 100 \mathrm{~mm}$. From Figure 4(a), it can be concluded that the maximum shear strength of sample 1 was $46.8 \mathrm{MPa}$. Clearly, stress, AE, and EMR changed almost similarly throughout the whole loading process. In the initial $30 \mathrm{~s}$, a self-balancing process of the shear mold occurred. Subsequently, shear force increased gradually. At 95 s, the magnetic signals of channel 5 (ch5: Figure 4(f)) and those of channel 8 (ch8: Figure 4(h)) showed an anomalous response. The signals increased rapidly and decreased immediately. Subsequently, the AE signals (Figure 4(e)) presented obvious changes when stress fluctuates slightly after $107 \mathrm{~s}$. Compared with AE signals, low-frequency magnetic signals occurred earlier. After $120 \mathrm{~s}$, stress increased quickly and the magnetic signals increased accordingly. At $160 \mathrm{~s}$, stress reached $43.4 \mathrm{MPa}$, which is close to the peak intensity. At this moment, the main macrocrack is formed. The stress fluctuates violently, whereas $\mathrm{AE}$ and magnetic signals reach the peak values. At $176 \mathrm{~s}$, the shear surface was cut through and stress suddenly dropped to 0 . The corresponding channel signals declined quickly.

The electric signals of different channels differed significantly during the whole loading process. The electric signals are slightly weak in Channel 2 (ch2: Figure 4(b)) and Channel 9 (ch9: Figure 4(d)), because the sensors of two channels did not contact with the rock surface directly. Before the main failure, the overall variation of electric signals was only about $2 \mathrm{mV}$ in these channels, whereas a huge amplitude of variations was detected after the development of main fracture. Considering the direct contact between electrode and the sample surface, the electric signals from channel 8 (ch8: Figure $4(\mathrm{c})$ ) were more sensitive and produced violent increase and reduction when stress fluctuated at $107 \mathrm{~s}$, which was consistent with the variation trends of $\mathrm{AE}$ and EMR. After $120 \mathrm{~s}$, the EMR signal had the increase trend, which is correlated with the continuous increase of stress. Later, pulse fluctuation became increasingly frequent in the early stage of shear failure, until the occurrence of the main failure and the signal variation amplitude of all channels reached the peak. In general, the electric signal was slightly correlated with stress but was closely related to fluctuation of the AE signal. However, the electric signal fluctuates upon stress fluctuation or generation of the AE signal.

3.2. Sample 2. Sample 2 was also collected from roof sandstone at the same position as Sample 1, but the size of shear surface in the former was $50 \mathrm{~mm} \times 100 \mathrm{~mm}$. Accordingly, the failure load was decreased to $67 \mathrm{kN}$, but they had the same shear strength. It could be concluded that there is a good correlation between low-frequency magnetic signal of channel 5 (ch5: Figure 5(f)), channel 7 (ch7: Figure 5(g)), and the stress. However, the magnetic signal of channel 8 (ch8: Figure 5(h)) was relatively weaker, showing no obvious variation throughout the loading process. During the loading process, two internal damages were detected at $75 \mathrm{~s}$ and $123 \mathrm{~s}$, and the main failure occurred at $140 \mathrm{~s}$. The AE signal had strong responses at these three time points, and it was stronger at $75 \mathrm{~s}$ than that at $123 \mathrm{~s}$. Interestingly, as shown in Figure 4(f), the EMR signal met its valley values around $75 \mathrm{~s}, 123 \mathrm{~s}$, and $140 \mathrm{~s}$. It is most striking around $123 \mathrm{~s}$. Meanwhile, in Figure 4(h), the EMR signal met its significant mutation response around $123 \mathrm{~s}$, while the response is less remarkable around $75 \mathrm{~s}$ and $140 \mathrm{~s}$. Compared with Sample 1, the overall electric-magnetic signal strength was significantly weaker. In particular, the high-frequency magnetic signal was not only weak but also poorly corresponding to the stress and AE signal.

The variation law of low-frequency electric signal was similar to that of Sample 1. The signals of channel 2 (ch2: Figure 5(b)) and channel 9 (ch9: Figure 5(d)) changed only slightly, about $1 \mathrm{mV}$ before the occurrence of main fracture. By contrast, they changed significantly after the main failure developed. Because of the higher sensitivity, the electric signal of channel 8 (ch8: Figure 5(c)) fluctuated greatly when stress began to change at $75 \mathrm{~s}$ and it presented the second change at $123 \mathrm{~s}$ when the overall basic value had reduced. This implied that the internal failure at $75 \mathrm{~s}$ brings about some negative charges surrounding the $8 \#$ test point. Because of the weak electroconductivity of the rock, this potential remained constant until the abundant new charges formed at the second fracture site $(123 \mathrm{~s})$. When the main failure occurred at $140 \mathrm{~s}$, the amplitude of signal fluctuation of channel 8 reached the maximum, but this was still smaller than that of Sample 1. This indicated that sample size could affect intensity of the electric signal, but they had consistent variation tendency.

\section{Discussion}

4.1. Electric-Magnetic Signal Generation Mechanism. The variable motion of charges is an important way to generate the electric-magnetic wave and includes two mechanisms, such as vibration or transition of electric dipole and relaxation of separated charges. Most mechanisms of EMR 


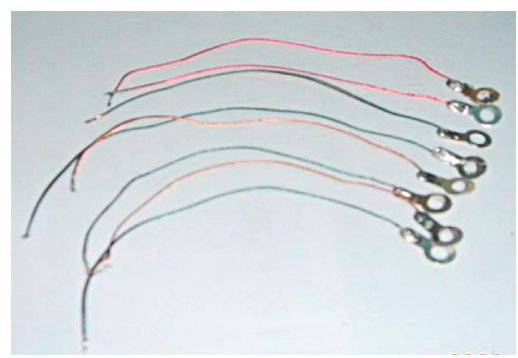

(a)

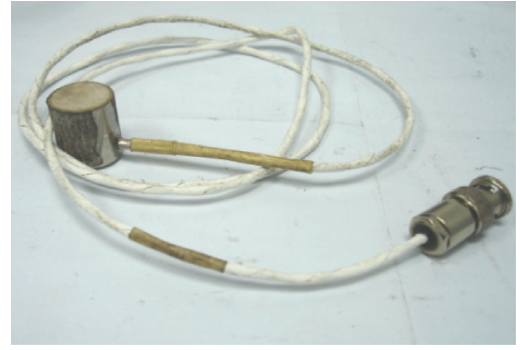

(b)

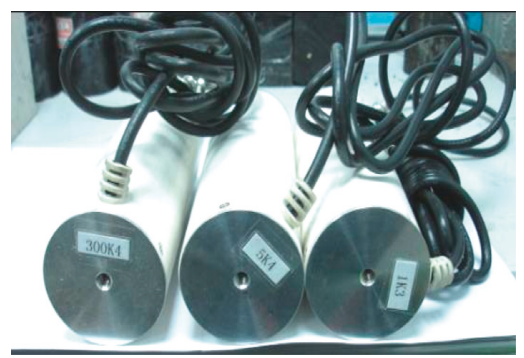

(c)

Figure 2: Sensors. (a) Electrode. (b) AE sensor. (c) Ferrite rod antenna.

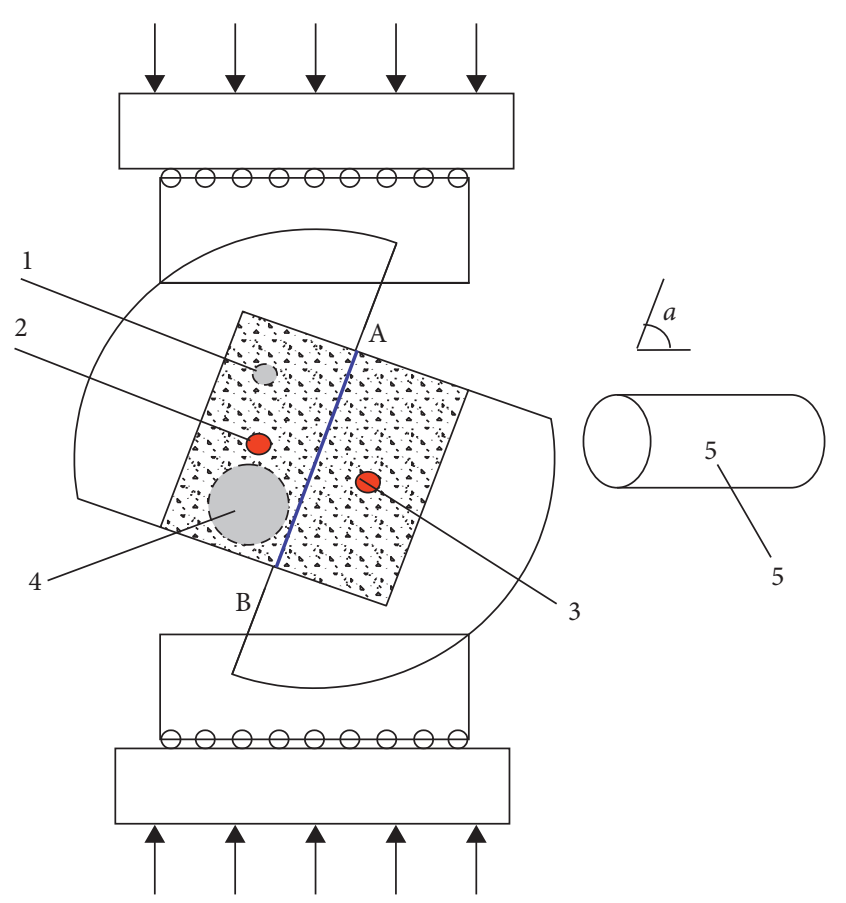

1-3: Electrodes

4: AE sensor

5: Ferrite rod antenna

FIGURE 3: Shearing equipment: 1-3: electrodes, 4: AE sensor; 5: ferrite rod antenna.

generation induced by deformation and failure of coal or rock are related to development of cracks. One is asymmetric charges along the axial direction of cracks, for example, electric dipole model. The other is positive and negative charges generated on cracks wall, such as variable motion of charges and relaxation of separated charges caused by friction electrification or piezoelectric effect. Therefore, it is necessary to study how charges are generated and moved when exploring the mechanism of EMR generation upon stress failure of coal or rock.

In these experiments, the rock suffered shear failure, which is different from tensional failure. Therefore, there is residual stress on crack surfaces even after sufficient sliding of these surfaces. Such residual frictional resistance could be regarded as the main source of stress. Meanwhile, the energy release rate of shear failure was two magnitudes higher than that of tensional failure. In other words, shear failure released an increased concentration of energy at the failure, which was related to different development processes of shear cracks and tensional cracks at the end point.

In the shearing process, charges of different polarities would be generated on the upper and lower shear surfaces, which were attributed to piezoelectric effect, frictional effect, and asymmetric breakages of crystal bonds (Figure 6).

Charge generation induced by the piezoelectric effect is mainly manifested during growth of cracks. With the extension of cracks, the stress of microunit on the upper surface of cracks changes significantly, thus attracting charges to some microunits containing piezoelectric materials. After further extension of the cracks, these microunits are distributed on the upper and lower surfaces of the cracks, making both upper and lower surfaces charged. When the main crack was cut through (i.e., the failure of materials), charges generated by the piezoelectric effect are reduced, which would contribute less to EMR signals.

EMR signal, induced by triboelectric charge, exists throughout the whole shear failure. However, its contributions are different in different stages. During the early loading period, due to the small pressure stress, the relative displacement between upper and lower surfaces of the cracks was very small and the electrification by friction was relatively weak. Nevertheless, the relative displacement between upper and lower surfaces increased significantly after the principal crack was cut through, accompanied by strong friction effect and increased generation of charges, both of which contributed to increased generation of EMR signals. Meanwhile, the contributions of friction effect to the EMR signal under shear failure changed with the shear angle. Obviously, friction played a greater role under a small shear angle and high-pressure stress.

These effects influence the whole shear failure process together, resulting in the continuous accumulation of charges on the upper and lower crack surfaces. Moreover, rock materials are of poor conductive features, which have low rate of charge release. Charges in rock materials will not disappear in a short period but instead move with the surface displacement. Because the total charge on crack surface increases continuously, the electric signal strengthens gradually in the whole failure process when viewed from the macroscopic perspective. Besides, the distance between the testing point and charges changed when upper and lower surfaces had relative displacement, thus causing the pulse fluctuation of the electric signal. This conforms to the variation law of the electric signal 


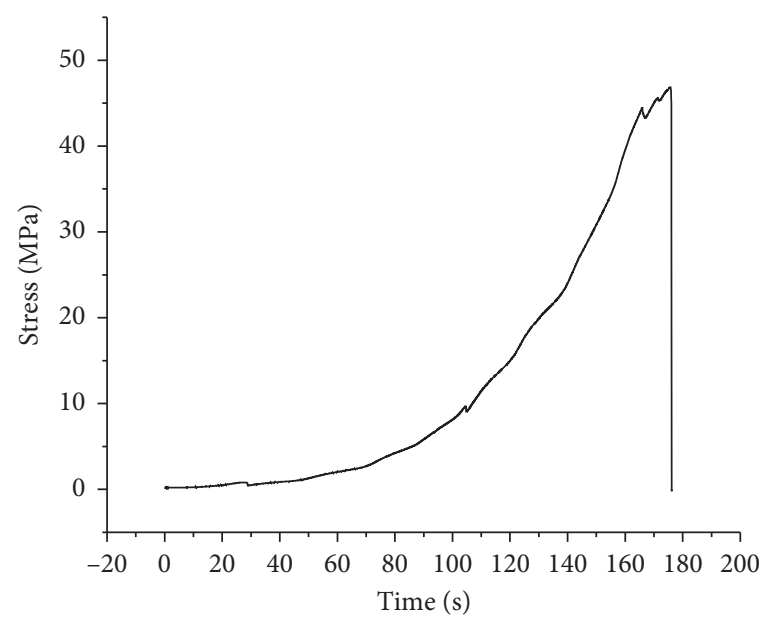

_ Load value

(a)

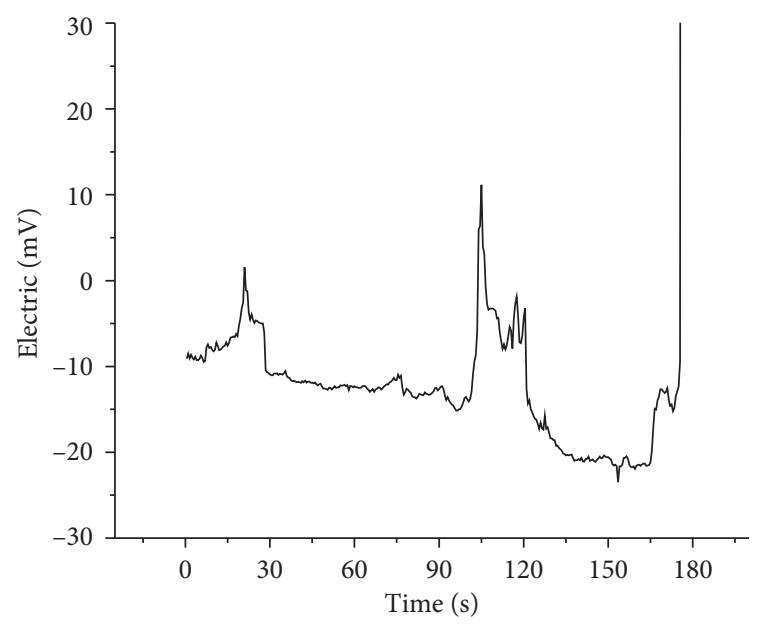

- Electric-ch8

(c)

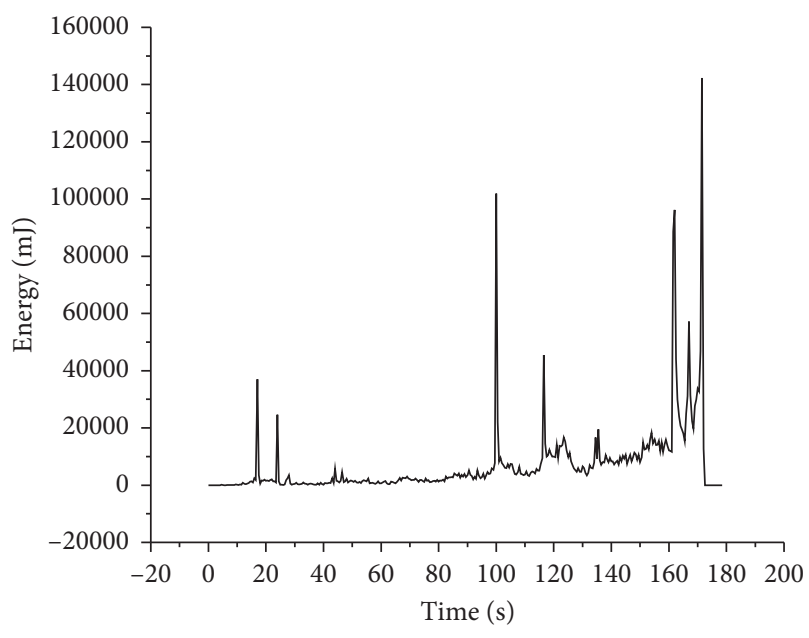

- AE-ch2

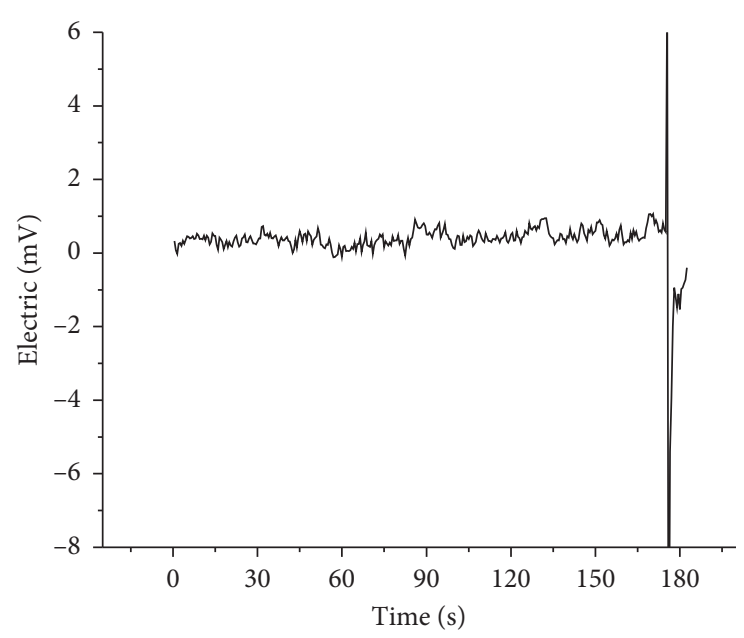

- Electric-ch2

(b)

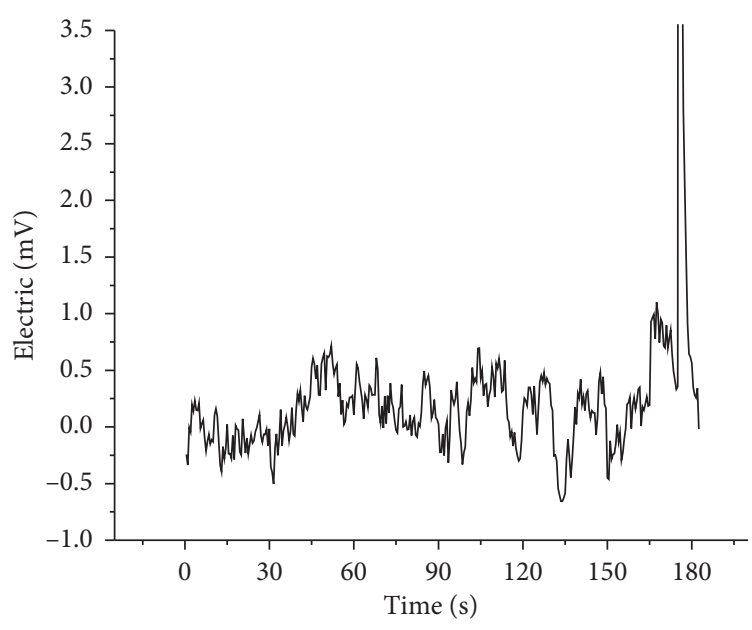

(d)

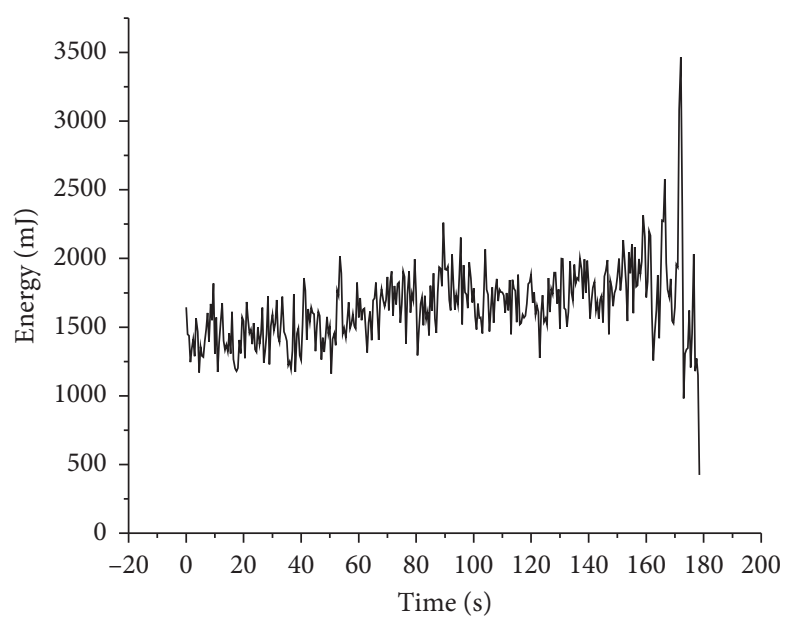

— EMR $(1 \mathrm{kHz})-\operatorname{ch} 5$

(f)

Figure 4: Continued. 


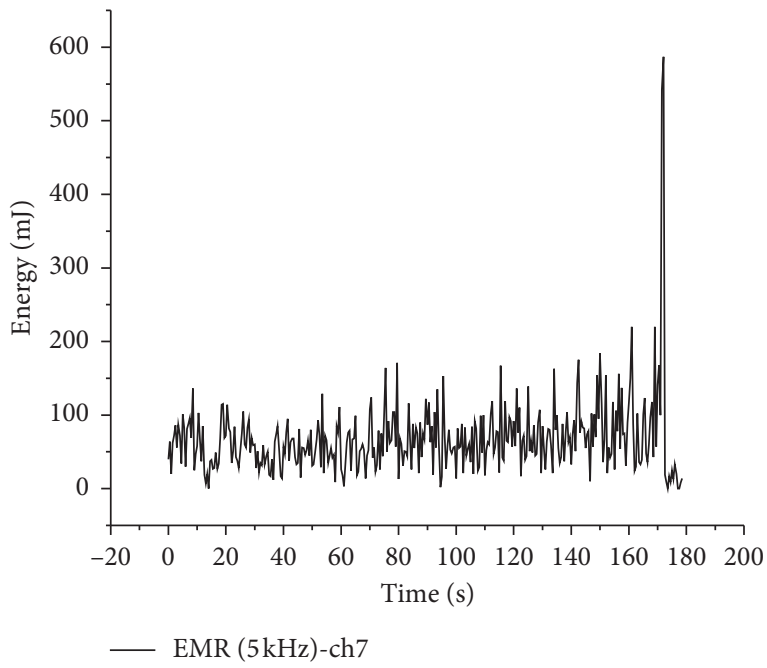

(g)

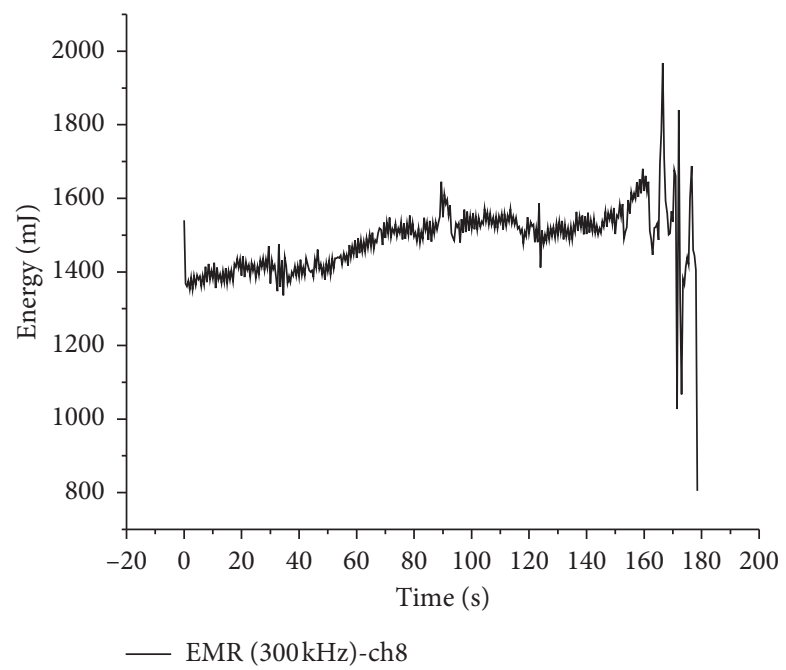

(h)

Figure 4: Electric-magnetic-acoustic signals of 1 \# rock sample (1 mm/min). (a) Stress-time. Electric signals of (b) ch2, (c) ch8, and (d) ch9. (e) Acoustic emission signals. Magnetic signals of (f) ch5, (g) ch7, and (h) ch8.

observed in the experiments. Furthermore, the motion of charges generates the EMR signal.

4.2. Correlation of Various Signals. At present, most scholars accept that sample damages and failures could be analyzed by variation of stress and $\mathrm{AE}$ signal. If the high correlation between electric-magnetic signals and stress as well as $\mathrm{AE}$ could be proved, it would lay foundations for using electricmagnetic signals to analyze sample damage and dynamic disasters of coal or rock. Based on the aforementioned analysis, we found that there is certain correlation between electric-magnetic signals and stress as well as AE. Meanwhile, the correlation between EMR signal of conventional frequency and $\mathrm{AE}$ as well as stress has been recognized by most scholars. However, no quantitative evaluation index was proposed for such correlation. In this paper, the correlation coefficient $(|r|)$ between electric-magnetic signals and stress as well as $\mathrm{AE}$ was calculated using the Origin mathematical software, which was used to evaluate their consistency.

Take the correlation between stress and electric signal (Figure 7(a)) for example. It demonstrated low linear correlation between two signals when the calculated maximum correlation coefficient $|r|<0.4$, significant correlation when $0.4 \leq|r|<0.7$, and high linear correlation when $0.7 \leq|r|<1$. When the delay $(\tau)$ corresponding to the maximum correlation coefficient is negative, stress changes earlier than the electric signal; otherwise, the electric signal changes earlier.

The calculated correlation coefficient between electricmagnetic signals of Sample 1 and stress as well as AE is shown in Figure 7. In most cases, $\tau$ is close to 0 , but in some cases, $\tau$ is not 0 . Corresponding to the maximum correlation coefficient between stress and electric signal of channel 8 (Figure $7(\mathrm{a})$ ), $\tau$ was $10 \mathrm{~s}$, indicating that electric signal changed earlier than stress. However, the electric signal data of channel 9 lagged for $2 \mathrm{~s}$ behind the stress (Figure 7(a)). In
Figure $7(\mathrm{~d})$, the delay between the magnetic signal of channel 5 and channel 8 and AE signal of channel 2 was $2 \mathrm{~s}$, indicating that the EMR signal changed earlier than the $\mathrm{AE}$ signal. Besides, correlation coefficients of electric signal had positive and negative values, which were related to accumulation of positive and negative charges in the electrode region. A similar phenomenon was observed in correlation coefficients of Sample 2 (Table 1). Meanwhile, we calculated another experimental data other than those used in this paper. According to various estimates, the correlation coefficient between electric signal and stress might be either positive or negative at equivalent probability. This was also caused by different charge polarities of different regions upon deformation or failure of the rock. When more positive charges accumulate in one region, the local electric signal increased generally, forming a positive correlation with stress variation. Otherwise, more negative charges accumulate, resulting in the negative correlation between the electric signal and stress.

Table 1 presents peak correlation coefficients of signals from Samples 1 and 2. Based on a comparison of 12 groups, correlation coefficients between electric-magnetic signals and stress were higher than those between electric-magnetic signals and $\mathrm{AE}$ in eight groups; correlation coefficients were close to those between electric-magnetic signals and $\mathrm{AE}$ in two groups; and correlation coefficients were smaller in two groups. With respect to correlation coefficients between stress and electric-magnetic signals, there were high linear correlation (in 6 groups), significant correlation (in 3 groups), and low linear correlation (in 3 groups). However, concerning the correlation coefficients between $\mathrm{AE}$ and electric-magnetic signals, there were no high linear correlation, significant correlation (in 9 groups), and low linear correlation (in 3 groups). Therefore, the correlation between magnetic signal and stress as well as $\mathrm{AE}$ was superior to that of the electric signal. 


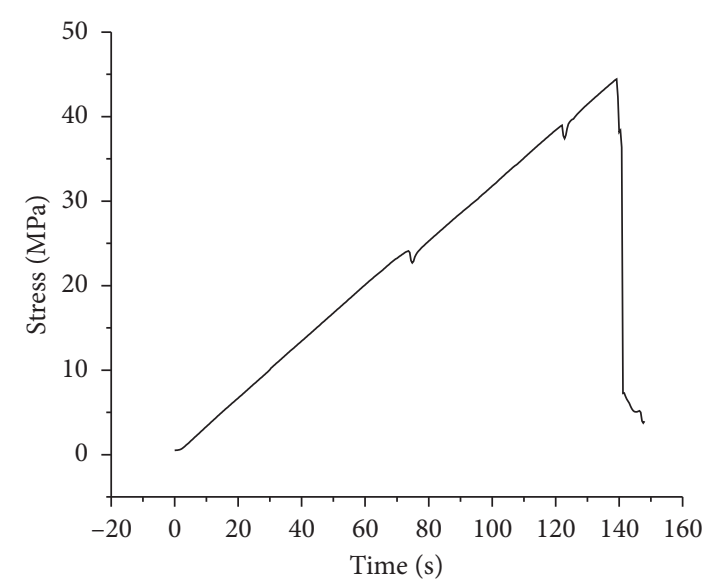

_ Load value

(a)

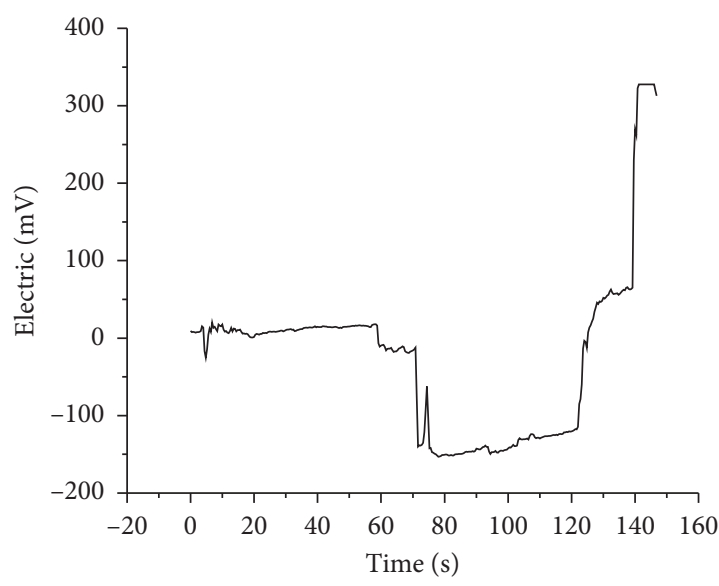

- Electric-ch8

(c)

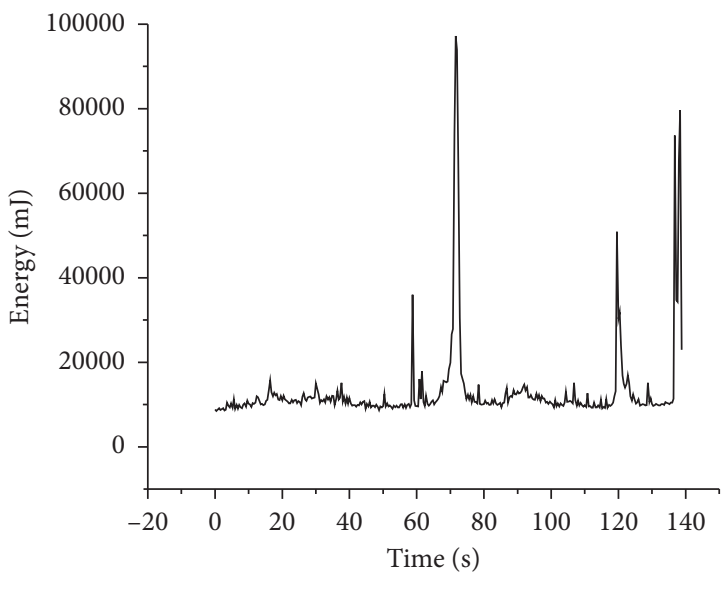

- AE-ch2

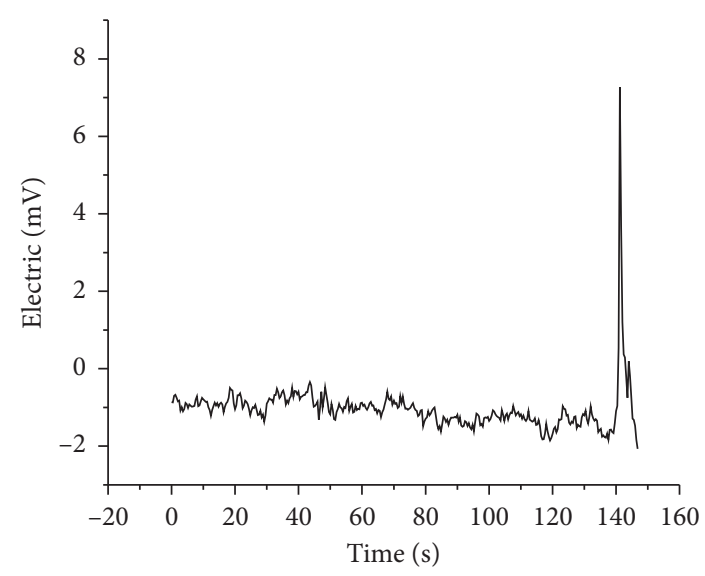

— Electric-ch2

(b)

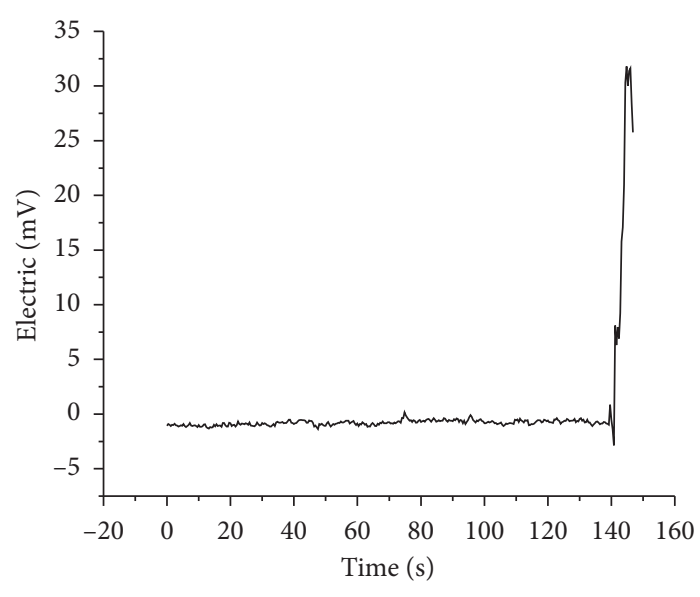

_ Electric-ch9

(d)

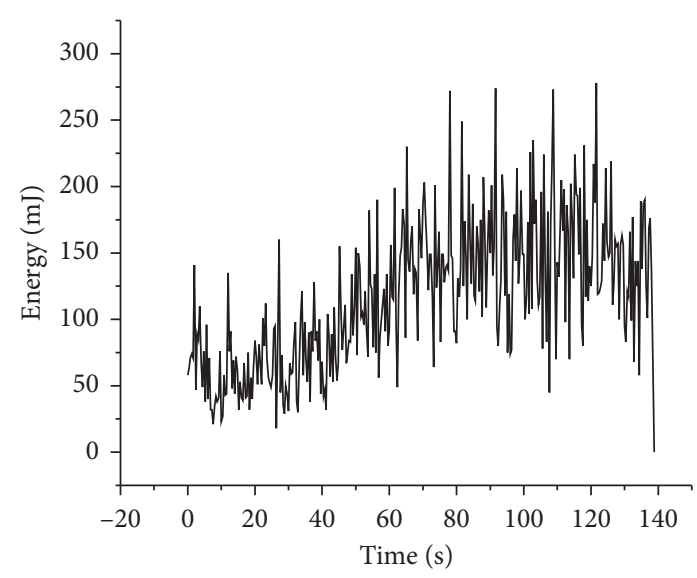

- EMR $(1 \mathrm{kHz})-\operatorname{ch} 5$

(f)

Figure 5: Continued. 


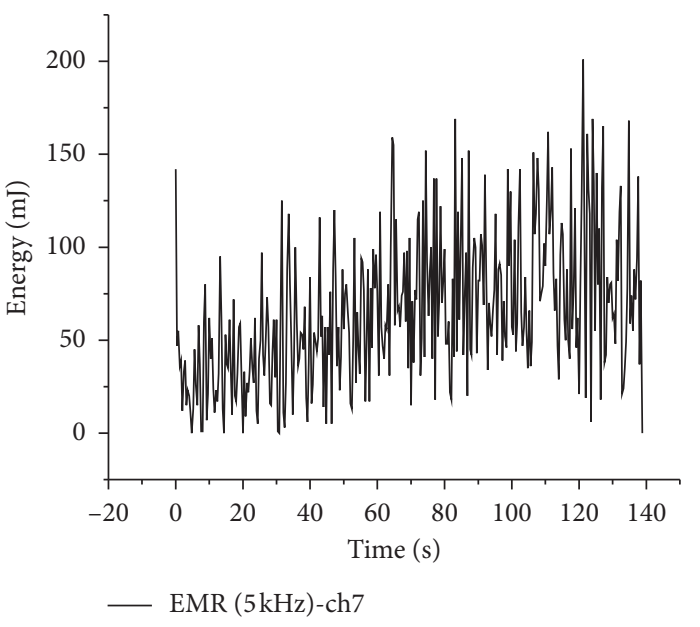

$(\mathrm{g})$

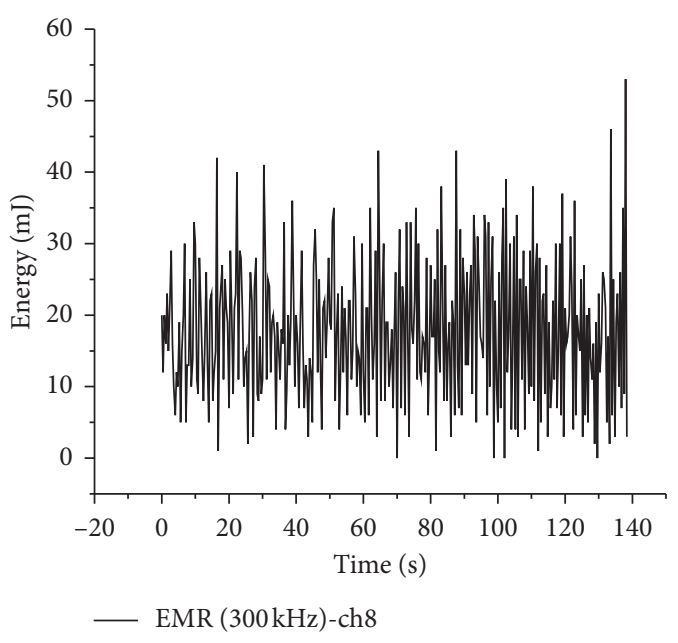

(h)

FigURE 5: Electric-magnetic-acoustic signals of 2\# rock sample (1 mm/min). (a) Stress-time. Electric signals of (b) ch2, (c) ch8, and (d) ch9. (e) Acoustic emission signals. Magnetic signals of (f) ch5, (g) ch7, and (h) ch8.

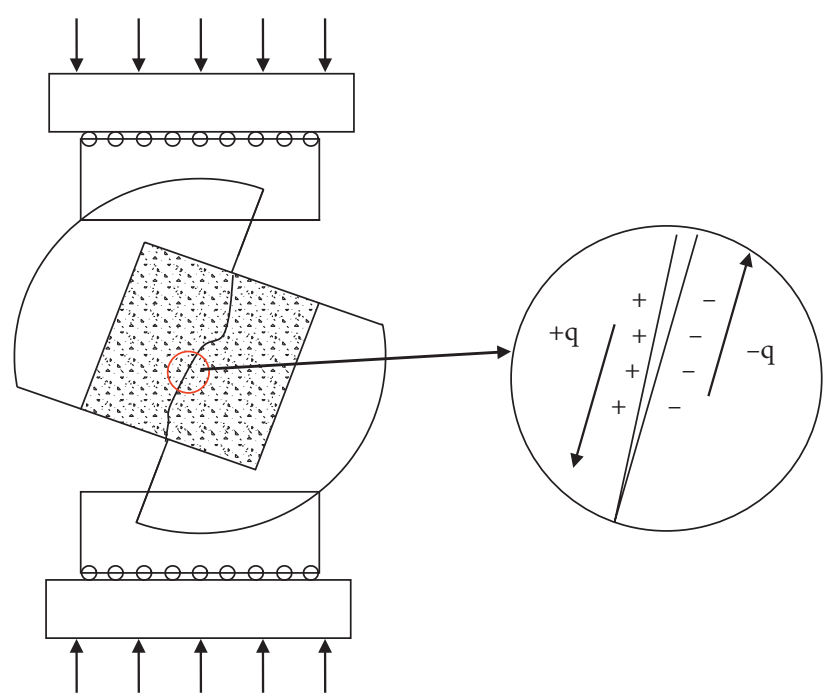

FIgURE 6: Direction of the electromagnetic field in shear failure.

It has to be pointed out that because correlation coefficient is calculated based on linear correlation calculation, the correlation coefficients between the data that seems correlated are low in reality. Figure 8 presents a comparison between AE energy and the electric signals of ch8. The electric signal enhanced when the AE signal strengthened, indicating the strong correlation between them. We believed that such correlation might be nonlinear, which explains the smaller calculated correlation coefficient.

4.3. Acoustic-Electric Coupling Model and Verification. From Figure 8, it could be seen that AE and electric signals were correlated with each other. As shown in Figure 8, at most moments, the acoustic emissions energy and electric values are relatively stable with some fluctuation. At some moments, when there is a relatively significant damage occurring inside the coal body (it is recorded that there is the pulsed increase of acoustic emission energy, which indicates a relatively significant microrupture inside the sample), the electric signal increases suddenly, which is cooperative with the acoustic emission energy. The response is correlated, especially when the sample ruptures, and both the electric signal and the acoustic emission signal exhibit a rapid increase to the maximum value. The variation mechanism of the electric signal can be viewed as follows: the increase of electric signals results from charge accumulation during the loaded failure, whereas their decrease results from deprivation of charges lost gradually. The speed of increase and decrease is also related to the coupling capacitance between electrode and samples. Based on the aforementioned theory, a circuit model was established for electric signal variation during shear failure of the rock (Figure 9).

In this model, the condenser voltage signal (the observed signal) is correlated with signal source $(S)$, resistance to 


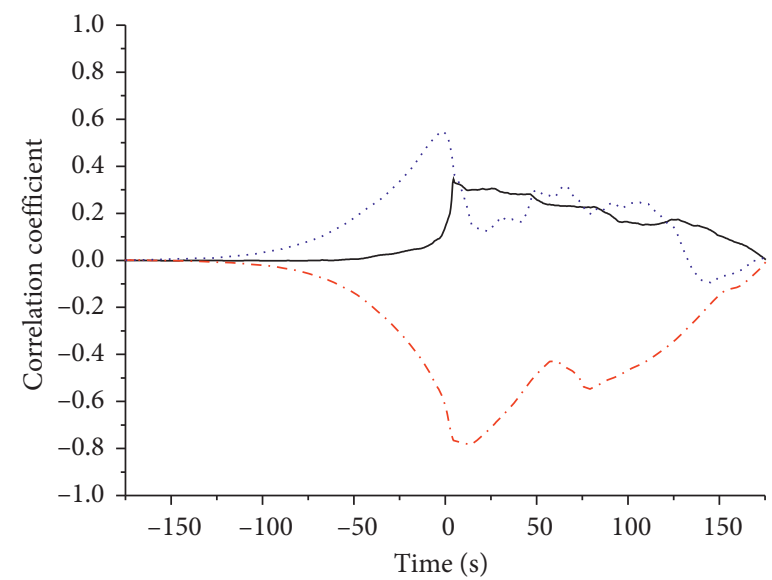

- Correlation of stress and electric-ch2

-. - Correlation of stress and electric-ch8

.... Correlation of stress and electric-ch9

(a)

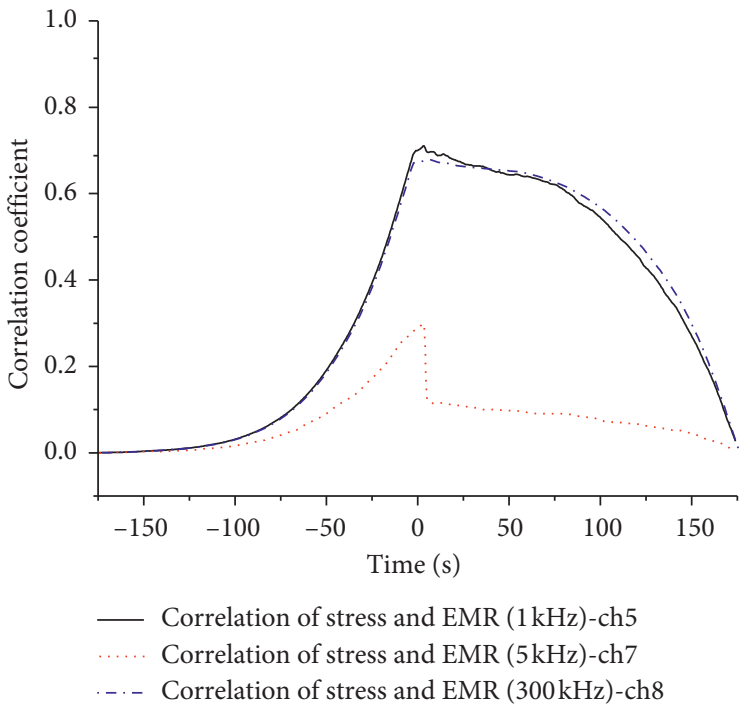

(c)

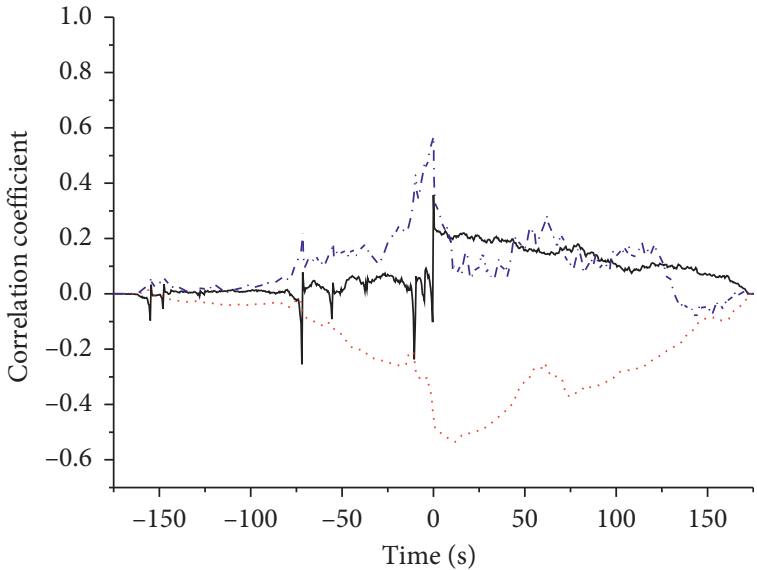

- Correlation of AE-ch2 and electric-ch2

... Correlation of AE-ch2 and electric-ch8

- Correlation of AE-ch2 and electric-ch9

(b)

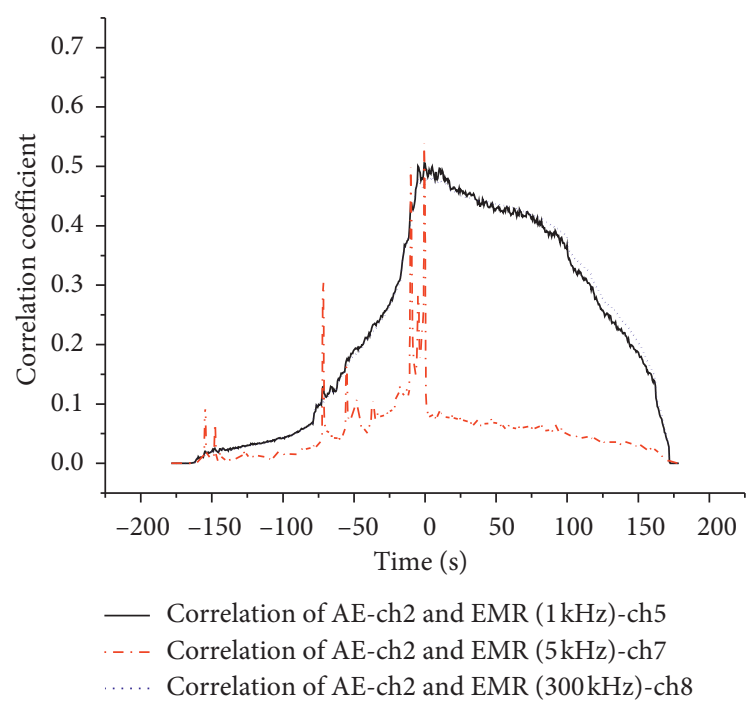

(d)

Figure 7: Correlation coefficient of signals (sample 1). (a) Stress vs. electric signals. (b) AE energy vs. electric signals. (c) Stress vs. EMR energy. (d) AE energy vs. EMR energy.

TABLE 1: Statistics on correlation coefficient values between two indexes of electric-magnetic signals as well as stress and AE energy.

\begin{tabular}{|c|c|c|c|c|c|}
\hline \multirow{2}{*}{ Sample number } & \multirow{2}{*}{ Channel number } & \multicolumn{4}{|c|}{ Correlation coefficients between two indexes } \\
\hline & & Electric-stress & Electric-AE & EMR-stress & EMR-AE \\
\hline \multirow{6}{*}{1} & Ch2 & 0.345 & 0.357 & - & - \\
\hline & Ch8 & -0.785 & -0.535 & - & - \\
\hline & Ch9 & 0.550 & 0.570 & - & - \\
\hline & Ch5 & - & - & 0.711 & 0.506 \\
\hline & $\mathrm{Ch} 7$ & - & - & 0.301 & 0.540 \\
\hline & Ch8 & - & - & 0.679 & 0.481 \\
\hline \multirow{6}{*}{2} & Ch2 & -0.855 & -0.406 & - & - \\
\hline & Ch8 & -0.601 & -0.193 & - & - \\
\hline & Ch9 & 0.137 & 0.386 & - & - \\
\hline & Ch5 & - & - & 0.925 & 0.452 \\
\hline & Ch7 & - & - & 0.867 & 0.421 \\
\hline & Ch8 & - & - & 0.772 & 0.411 \\
\hline
\end{tabular}




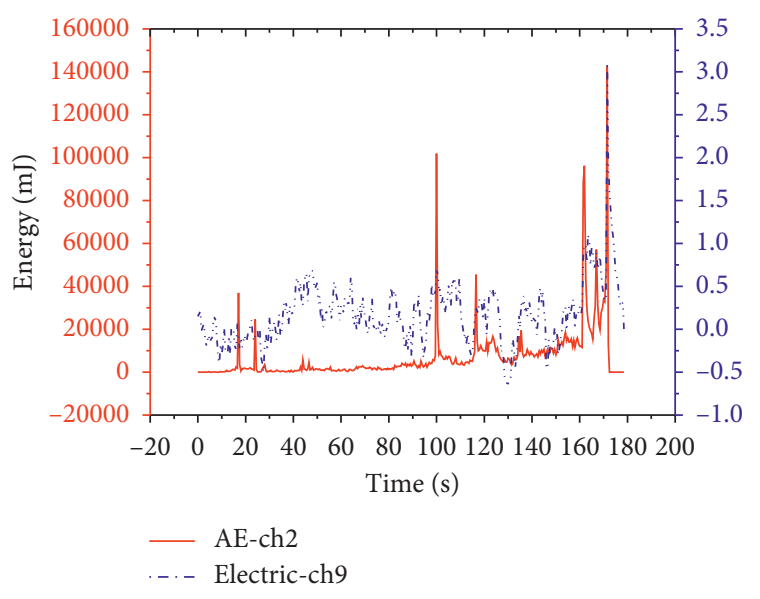

(a)

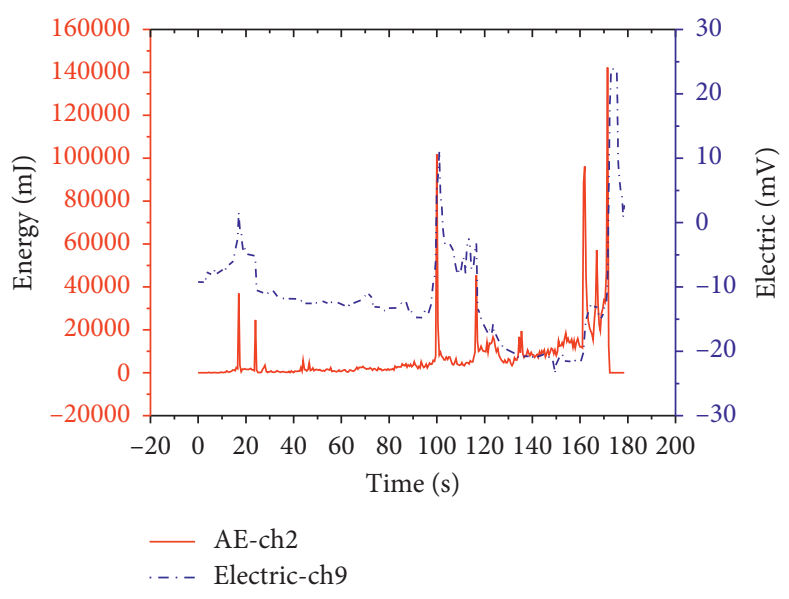

(b)

Figure 8: Comparison between AE energy and the electric signals of ch8. (a) Sample 1. (b) Sample 2. Light blue dotted lines and orange arrows indicate abnormal response of signals.

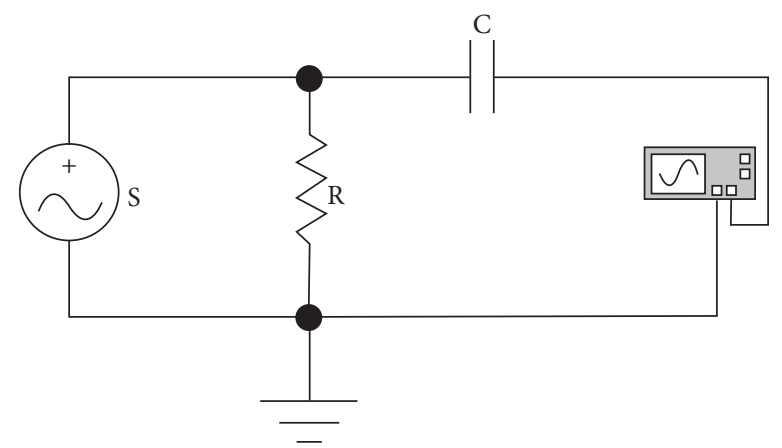

Figure 9: Acoustic-electric coupling model.

ground $(R)$, and capacitance $(C)$. The following charge balance exists:

$$
\int_{t_{0}}^{t_{1}}\left(a \times E-\left(\frac{U}{R}\right)\right) d_{t}=\left(U_{t_{1}}-U_{t_{0}}\right) \times C
$$

where $E$ represents the accumulated AE energy, $a$ represents the ratio between electric charge quantity and accumulated $\mathrm{AE}$ energy, and $U$ denotes the voltage of the condenser.

Size of $S$ is related to generation and development of cracks, which is proportional to AE energy. Accumulated AE energy in $\Delta t$ is $E$. The quantity of electric charge generated by cracks is $q_{l}=a \times E$, and the quantity of electric charge released to ground is $q_{s}=\left(\left(U_{t_{1}}+U_{t_{0}}\right) / 2 R\right)$. The overall charge balance can be simplified as

$$
\begin{aligned}
a E-\frac{U_{t_{1}}+U_{t_{0}}}{2 R} & =\left(U_{t_{1}}-U_{t_{0}}\right) \times C, \\
a E & =U_{t_{1}}\left(C+\frac{1}{2 R}\right)-U_{t_{0}}\left(C-\frac{1}{2 R}\right), \\
\frac{2 a R}{C+2 R} E & =U_{t_{1}}-U_{t_{0}} \times \frac{C-2 R}{C+2 R} .
\end{aligned}
$$

Let $b=(2 a R /(C+2 R))$ and $c=((C-2 R) /(C+2 R))$, equation (2) can be expressed as follows:

$$
b E=U_{t_{1}}-c U_{t_{0}} .
$$

Using equation (3), the collected electric signal was converted through adjusting $c$ and its correlation with $\mathrm{AE}$ is displayed in Figure 10.

As shown in Figure 10, the evolution characteristics of AE energy and converted electric signal response are similar and cooperative. For example, in the majority of moments, the AE energy and converted electric values are low and stable in Figure 10(a). Around $17 \mathrm{~s}$ and $24 \mathrm{~s}$, both of them show growth spurt. Around $100 \mathrm{~s}$ and $116 \mathrm{~s}$, the cooperative anomalous characteristics are more significant. At $171 \mathrm{~s}$, both values reach their maximum values cooperatively. Hence, there is a strong correlation exits between AE energy and electric signal with both showing a similar variation tendency, which will lay foundations for further interpreting the generation mechanism of the electric signal by improving its applications. 


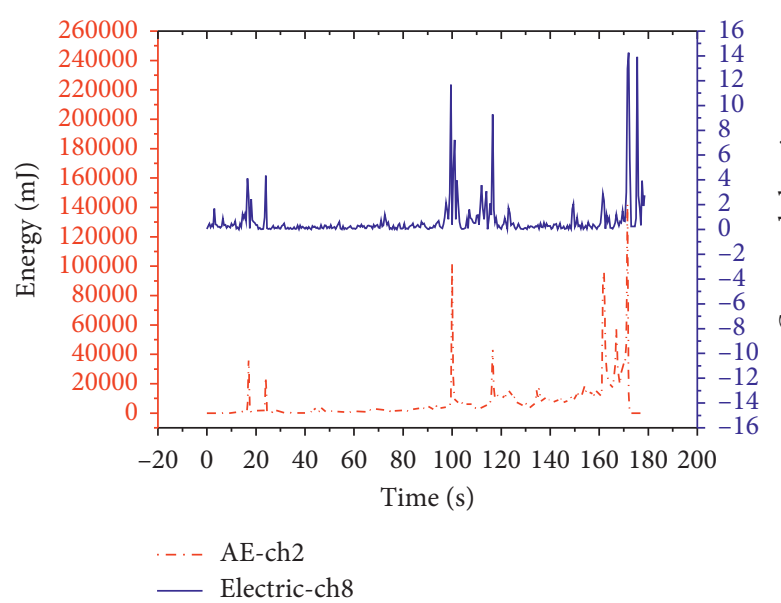

(a)

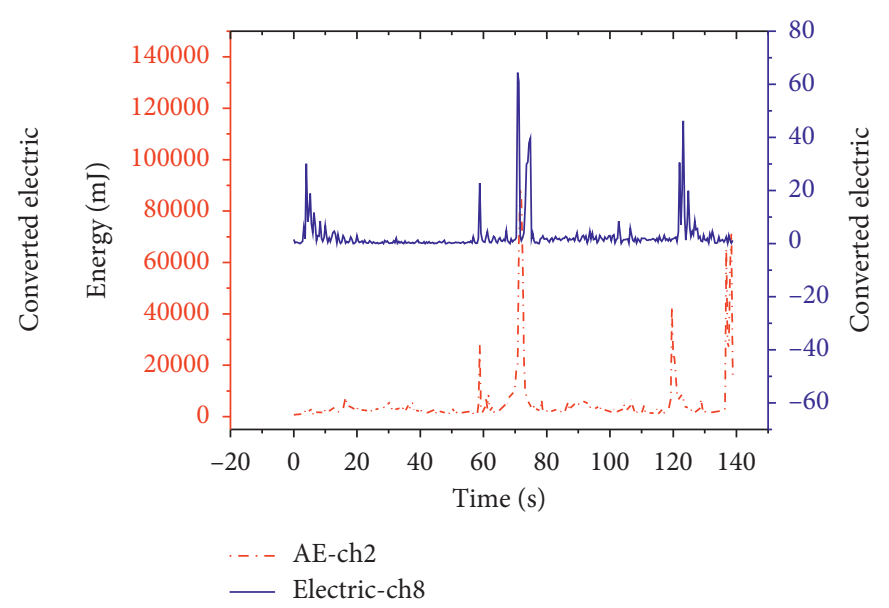

(b)

Figure 10: Correlation between AE energy and converted electric signals.

\section{Conclusions}

In this paper, the laboratory experiments of sandstone samples under shear loading were carried out; meanwhile, the electric-magnetic-acoustic signal regularity was measured and analyzed comparatively. The results were obtained as followed:

(1) The electric-magnetic-acoustic signals are generated during the shear failure of the rock. The magnetic signal is highly correlated with stress and AE signal, but the electric signal changes randomly. When the main failure occurs, the amplitude of the electric signal fluctuation is larger than that of magnetic and AE signals. The strength of electric-magneticacoustic signals is basically proportional to the rock strength, the energy released from failure, the number of cracks, and so on.

(2) The correlation coefficients between electricmagnetic signal and stress as well as AE are calculated and used for quantitative evaluation of the correlation degree between signals. The significant or highly linear proportion between the electricmagnetic signal and stress as well as AE reaches $75 \%$. The correlation degree between the electricmagnetic signal and stress as well as AE is even higher.

(3) A coupling model between AE and electric signal is established, in which the magnitude of electric signal is related to AE energy $(E)$, resistance to ground $(R)$, and other parameters. There is a good correlation between the electric signal and AE energy, which confirms the variation law of the electric signal and verifies rationality of the model.

\section{Data Availability}

The data used to support the findings of this study are included within the article.

\section{Conflicts of Interest}

The authors declare that there are no conflicts of interest regarding the publication of this paper.

\section{Authors' Contributions}

Huilin Jia and Yue Niu contributed equally to this work.

\section{Acknowledgments}

We thank the English editing contribution to the paper by Benjamin Shaw, Director, Liwen Bianji (Edanz Group China). The authors gratefully acknowledge the support provided by the project funded by the general program of the National Natural Science Foundation of China (51674254) and Priority Academic Program Development of Jiangsu Higher Education Institutions and the Fundamental Research Fund for the Central Universities (nos. 2014ZDPY23 and 2015XKZD04).

\section{References}

[1] A. Franco and A. R. Diaz, "The future challenges for "clean coal technologies": joining efficiency increase and pollutant emission control," Energy, vol. 34, no. 3, pp. 348-354, 2009.

[2] L. Quesada Carballo, M. D. R. Perez Perez, D. Cantador Fernández, A. Caballero Amores, and J. M. Fernández Rodríguez, "Optimum particle size of treated calcites for $\mathrm{CO}_{2}$ capture in a power plant," Materials, vol. 12, no. 8, p. 1284, 2019.

[3] Q. Shi and B. Qin, "Experimental research on gel-stabilized foam designed to prevent and control spontaneous combustion of coal," Fuel, vol. 254, article 115558, 2019.

[4] J. Whyatt, "Dynamic failure in deep coal: recent trends and a path forward," in Proceedings of the 27th International Conference on Ground Control in Mining, pp. 29-31, Morgantown, WV, USA, July 2008.

[5] J. Ahirwal and S. K. Maiti, "Assessment of soil properties of different land uses generated due to surface coal mining 
activities in tropical sal (Shorea robusta) forest, India," $C A$ TENA, vol. 140, pp. 155-163, 2016.

[6] W. Cheng, X. Hu, J. Xie, and Y. Zhao, "An intelligent gel designed to control the spontaneous combustion of coal: fire prevention and extinguishing properties," Fuel, vol. 210, pp. 826-835, 2017.

[7] S. Polesek-Karczewska, "Estimation of the structure-related share of radiation heat transfer in a carbonised packed coal bed," Fuel, vol. 195, pp. 243-252, 2017.

[8] D. N. Espinoza, J.-M. Pereira, M. Vandamme, P. Dangla, and S. Vidal-Gilbert, "Desorption-induced shear failure of coal bed seams during gas depletion," International Journal of Coal Geology, vol. 137, pp. 142-151, 2015.

[9] W. J. Gale and R. L. Blackwood, "Stress distributions and rock failure around coal mine roadways," International Journal of Rock Mechanics and Mining Sciences \& Geomechanics Abstracts, vol. 24, no. 3, pp. 165-173, 1987.

[10] Z.-L. Li, X.-Q. He, L.-M. Dou, D.-Z. Song, G.-F. Wang, and X.-L. Xu, "Investigating the mechanism and prevention of coal mine dynamic disasters by using dynamic cyclic loading tests," Safety Science, vol. 115, pp. 215-228, 2019.

[11] S. Marland, A. Merchant, and N. Rowson, "Dielectric properties of coal," Fuel, vol. 80, no. 13, pp. 1839-1849, 2001.

[12] T. Shiotani, M. Ohtsu, and K. Ikeda, "Detection and evaluation of $\mathrm{AE}$ waves due to rock deformation," Construction and Building Materials, vol. 15, no. 5-6, pp. 235-246, 2001.

[13] M. Heap, S. Vinciguerra, and P. Meredith, "The evolution of elastic moduli with increasing crack damage during cyclic stressing of a basalt from Mt. Etna volcano," Tectonophysics, vol. 471, no. 1-2, pp. 153-160, 2009.

[14] F.-Q. Su, K.-I. Itakura, G. Deguchi, and K. Ohga, "Monitoring of coal fracturing in underground coal gasification by acoustic emission techniques," Applied Energy, vol. 189, pp. 142-156, 2017.

[15] C. Khazaei, J. Hazzard, and R. Chalaturnyk, "Damage quantification of intact rocks using acoustic emission energies recorded during uniaxial compression test and discrete element modeling," Computers and Geotechnics, vol. 67, pp. 94-102, 2015.

[16] Y. Liang, Q. Li, Y. Gu, and Q. Zou, "Mechanical and acoustic emission characteristics of rock: effect of loading and unloading confining pressure at the postpeak stage," Journal of Natural Gas Science and Engineering, vol. 44, pp. 54-64, 2017.

[17] X. Wang, X. Liu, E. Wang et al., "Experimental research of the AE responses and fracture evolution characteristics for sandparaffin similar material," Construction and Building Materials, vol. 132, pp. 446-456, 2017.

[18] B. Kong, Z. Li, and E. Wang, "Fine characterization rock thermal damage by acoustic emission technique," Journal of Geophysics and Engineering, vol. 15, no. 1, pp. 1-12, 2017.

[19] I. Yamada, K. Masuda, and H. Mizutani, "Electromagnetic and acoustic emission associated with rock fracture," Physics of the Earth and Planetary Interiors, vol. 57, no. 1-2, pp. 157-168, 1989.

[20] M. H. Adams, "Some observations of electromagnetic signals prior to California earthquakes," Journal of Scientific Exploration, vol. 4, pp. 137-152, 1990.

[21] A. Misra, R. C. Prasad, V. S. Chauhan, and B. Srilakshmi, "A theoretical model for the electromagnetic radiation emission during plastic deformation and crack propagation in metallic materials," International Journal of Fracture, vol. 145, no. 2, pp. 99-121, 2007.
[22] F. Freund and D. Sornette, "Electro-magnetic earthquake bursts and critical rupture of peroxy bond networks in rocks," Tectonophysics, vol. 431, no. 1-4, pp. 33-47, 2007.

[23] S. O. Gade, U. Weiss, M. A. Peter, and M. G. R. Sause, "Relation of electromagnetic emission and crack dynamics in epoxy resin materials," Journal of Nondestructive Evaluation, vol. 33, no. 4, pp. 711-723, 2014.

[24] A. Carpinteri, G. Lacidogna, A. Manuello, G. Niccolini, A. Schiavi, and A. Agosto, "Mechanical and electromagnetic emissions related to stress-induced cracks," Experimental Techniques, vol. 36, no. 3, pp. 53-64, 2012.

[25] E. Wang, H. Jia, D. Song, N. Li, and W. Qian, "Use of ultralow-frequency electromagnetic emission to monitor stress and failure in coal mines," International Journal of Rock Mechanics and Mining Sciences, vol. 70, pp. 16-25, 2014.

[26] E. Wang, X. He, J. Wei, B. Nie, and D. Song, "Electromagnetic emission graded warning model and its applications against coal rock dynamic collapses," International Journal of Rock Mechanics and Mining Sciences, vol. 48, no. 4, pp. 556-564, 2011.

[27] B. Kong, E. Wang, Z. Li, and Y. Niu, "Time-varying characteristics of electromagnetic radiation during the coalheating process," International Journal of Heat and Mass Transfer, vol. 108, pp. 434-442, 2017.

[28] Y. Niu, X. Song, Z. Li et al., "Study on EP response to compression-induced damage of coal-measure rock and the mechanism behind such response," Journal of Geophysics and Engineering, vol. 16, no. 1, pp. 242-252, 2019.

[29] Y. Niu, C. Wang, E. Wang, and Z. Li, "Experimental study on the damage evolution of gas-bearing coal and its electric potential response," Rock Mechanics and Rock Engineering, pp. 1-16, 2019.

[30] S. Li, S. Hu, B. Xie et al., "Influence of pleat geometry on the filtration and cleaning characteristics of filter media," Separation and Purification Technology, vol. 210, pp. 38-47, 2019.

[31] F. Freund, "Charge generation and propagation in igneous rocks," Journal of Geodynamics, vol. 33, no. 4-5, pp. 543-570, 2002.

[32] Z.-H. Li, E.-Y. Wang, Z.-T. Liu, X.-Y. Song, and Y.-N. Li, "Study on characteristics and rules of surface potential during coal fracture," Journal of China University of Mining \& Technology, vol. 2, 2009.

[33] Z. Li, Y. Niu, E. Wang et al., "Experimental study on electric potential response characteristics of gas-bearing coal during deformation and fracturing process," Processes, vol. 7, no. 2, p. $72,2019$. 


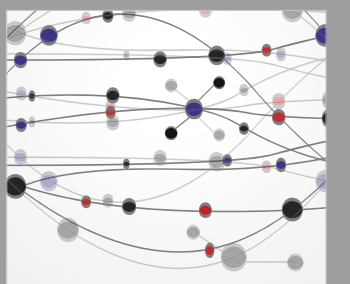

The Scientific World Journal
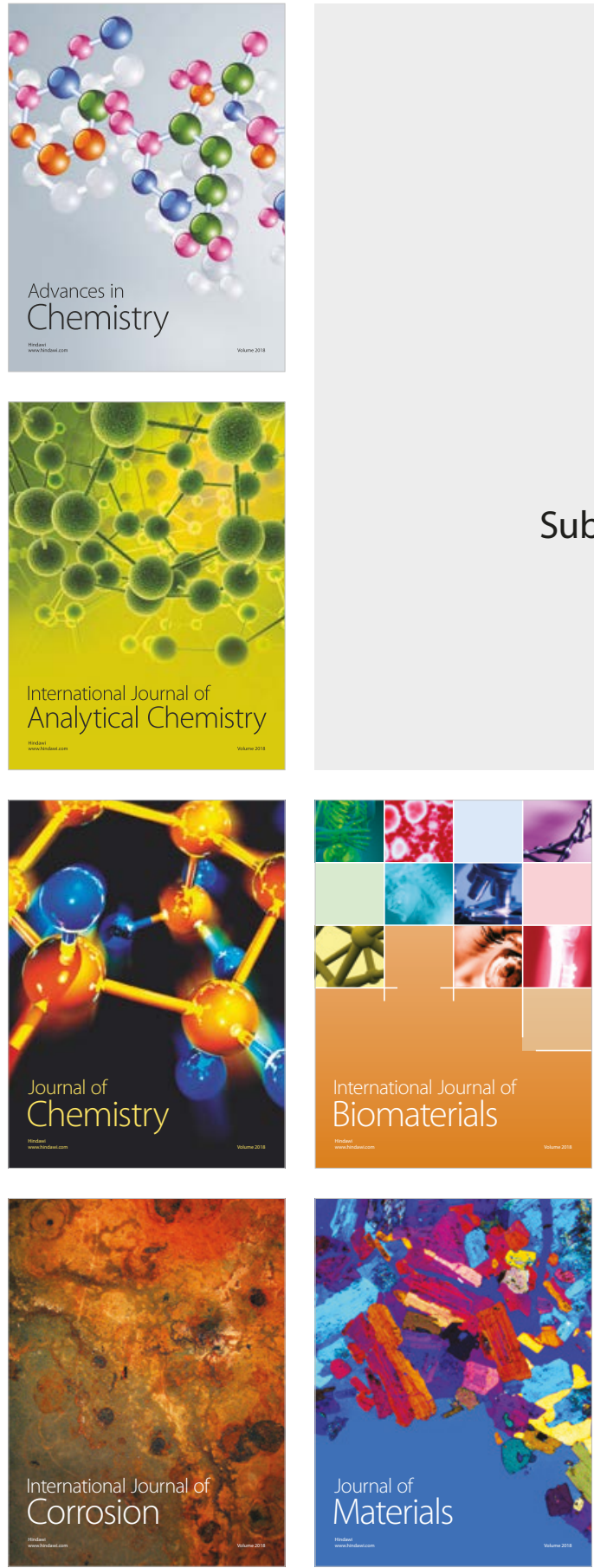

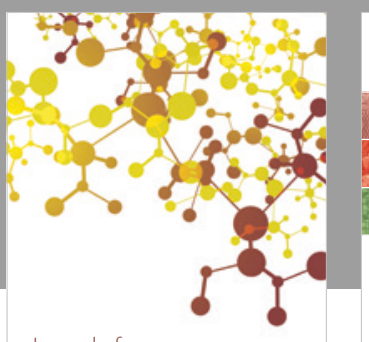

Journal of

Applied Chemistry
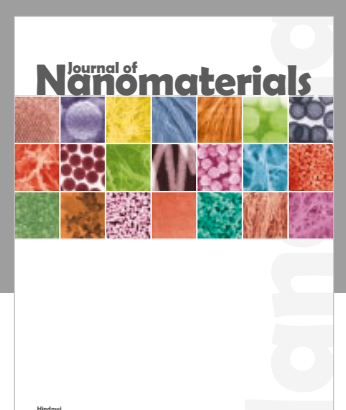

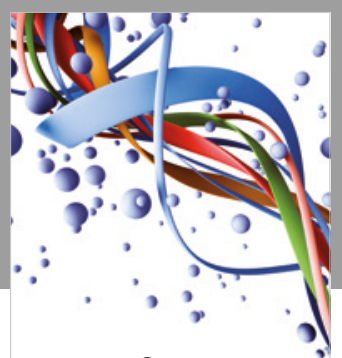

Scientifica

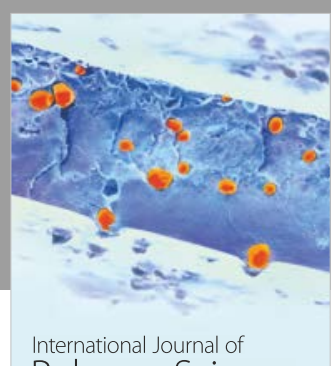

Polymer Science

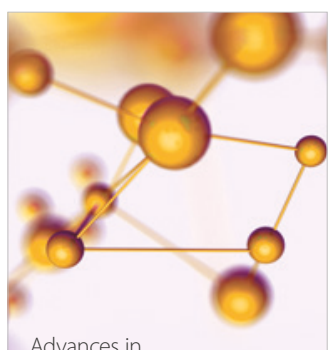

Physical Chemistry
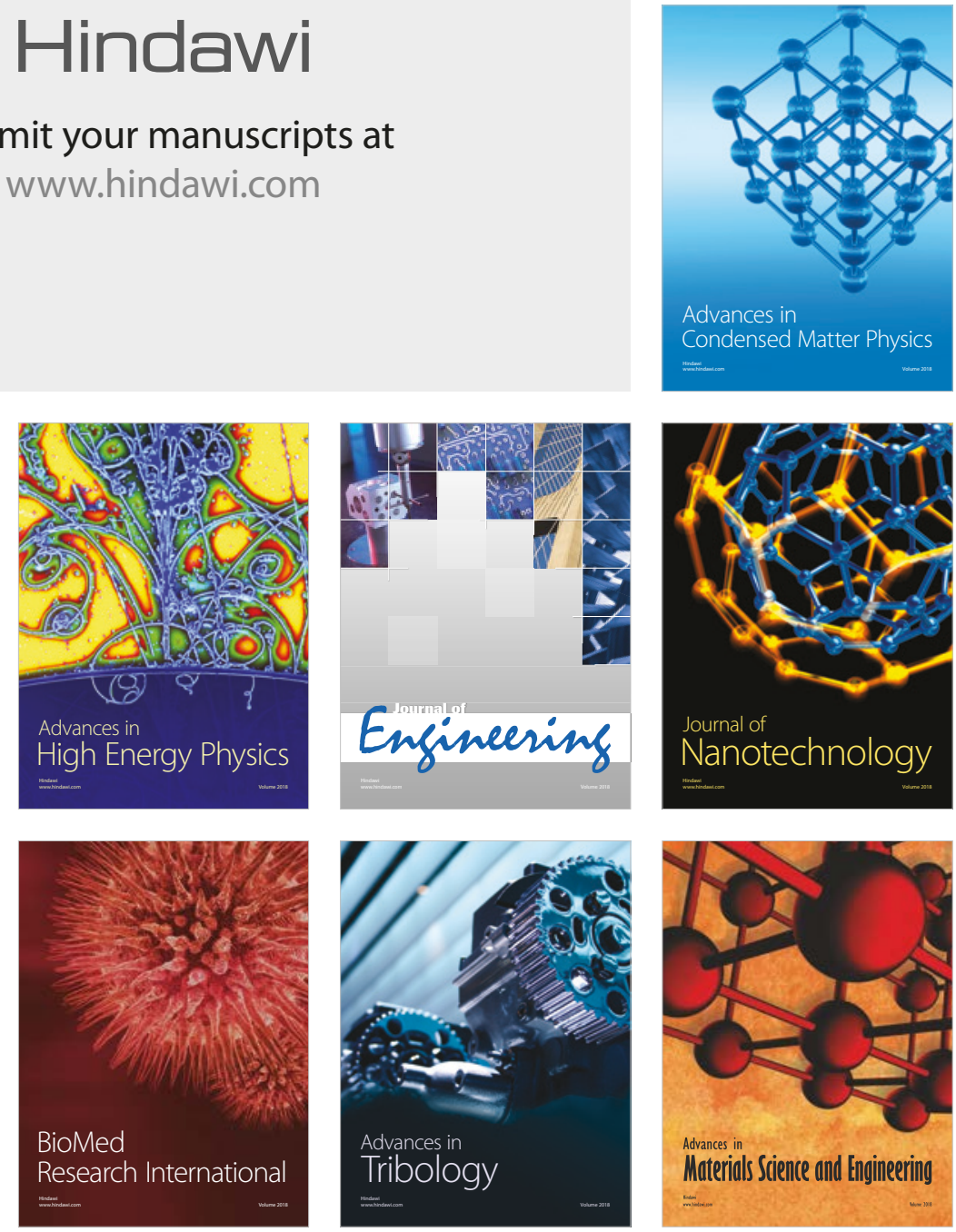